\title{
Perforated Amebic Huge Liver Abscess Successfully Treated with Metronidazole
}

\author{
Takuhiro Ugajin ${ }^{1}$, Hiroyuki Miyatani ${ }^{1}$, Yoshiaki Watanabe ${ }^{2}$, \\ Junji Nishida $^{3}$ and Yukio Yoshida ${ }^{1}$
}

Key words: amebic liver abscess, perforation, metronidazole, HIV

(Inter Med 47: 879-880, 2008)

(DOI: 10.2169/internalmedicine.47.0995)
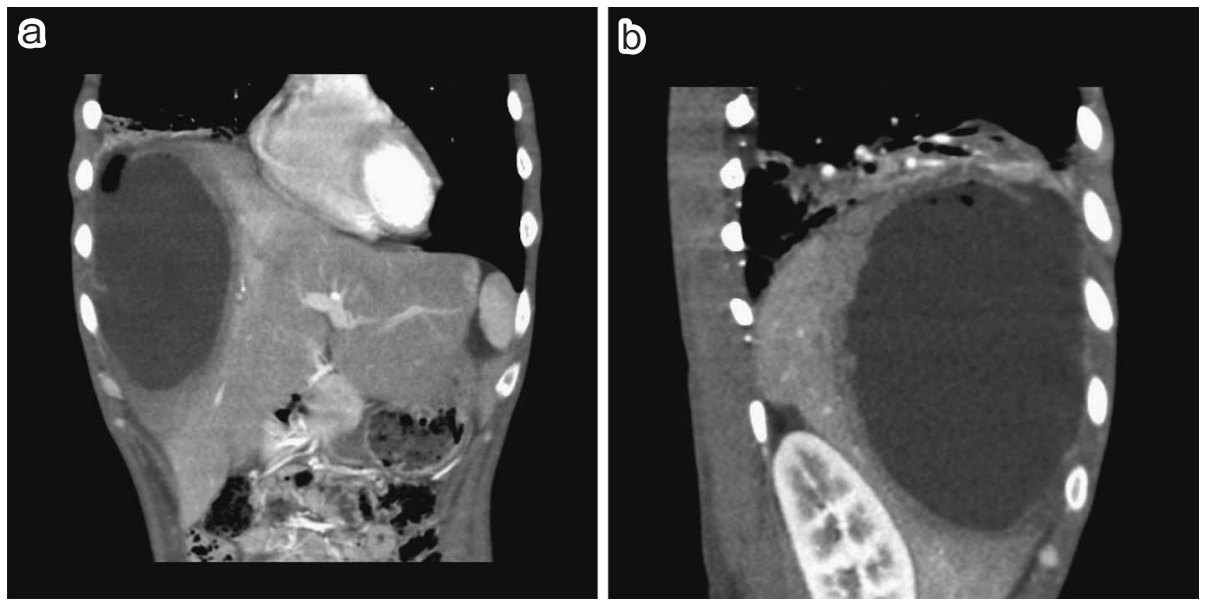

Picture 1. Computed tomography showed that a huge cystic lesion in the right lobe of the liver (8 $\times 15 \mathrm{~cm}$ ) had ruptured into the chest cavity and come into direct contact with right lung. Air in the lesion was probably due to a bronchobiliary fistula or co-infection of gas-producing bacteria.

A 31-year-old man complained of right hypochondralgia, high grade fever and productive cough. He was a drug abuser and homosexual. Chest X-ray revealed an infiltrate of the right lower lobe. Leukocytosis and elevation of CRP were detected. Computed tomography (CT) showed that a huge cystic lesion in the right lobe of the liver had perforated into the chest cavity and had come into direct contact with the right lung (Picture 1a, 1b). Anti-HIV antibody was positive. Liver abscess was diagnosed and empirical therapy was immediately started with oral metronidazole $750 \mathrm{mg}$ three times and intravenous imipenem/cilastatin $0.5 \mathrm{~g}$ twice daily. Although echo-guided percutaneous transhepatic drainage was unsuccessful, metronidazole alleviated his symptoms within several days. Antiamebic antibody later turned out to be positive. Despite incubation of the pus and micro- scopic examination, no bacteria were isolated and no amoeba could be found. He was discharged 50 days after admission. CT showed the liver abscess to be significantly reduced 60 days after starting treatment with metronidazole. Among patients with amebic liver abscess, mortality is 5\% but it increases to $17 \%$ in those with perforated abscess (1). Administration of metronidazole prior to definite diagnosis of amebiasis has been said to be very important (2) and effective in preventing septic shock even in the present case of amebic liver abscess which had perforated into the chest cavity leading to empyema.

${ }^{1}$ Division of Gastroenterology, Saitama Medical Center, Jichi Medical University, Saitama, ${ }^{2}$ Division of Radiology, Saitama Medical Center, Jichi Medical University, Saitama and ${ }^{3}$ Division of Hematology, Saitama Medical Center, Jichi Medical University, Saitama Received for publication February 7, 2008; Accepted for publication February 14, 2008 Correspondence to Dr. Takuhiro Ugajin, tugajin@omiya.jichi.ac.jp 
Inter Med 47: 879-880, 2008 DOI: 10.2169/internalmedicine.47.0995

\section{References}

1. Meng XY, Wu JX. Perforated amebic liver abscess: clinical analysis of 110 cases. South Med J 87: 985-990, 1994.

2. Motoyama K, Kaneko J, Ando M, et al. A case of multiple liver abscess difficult to diagnose preoperatively. Nippon Rinshou Gekagakkai Zasshi (Journal of Japan Surgical Association) 67: 1079-1084, 2006 in Japanese, Abstract in English).

(C) 2008 The Japanese Society of Internal Medicine http://www.naika.or.jp/imindex.html 